Jing Qian, Chao Fu, Xianyou Wu, Xianghai Ran* and Wei Nie*

\title{
Promotion of poly(vinylidene fluoride) on thermal stability and rheological property of ethylene-tetrafluoroethylene copolymer
}

https://doi.org/10.1515/epoly-2018-0057

Received March 21, 2018; accepted May 16, 2018; previously published online August 18, 2018

Abstract: In this work, the thermal stability, rheological properties and mechanical properties of ethylenetetrafluoroethylene copolymer (ETFE)/poly(vinylidene fluoride) (PVDF) blends were investigated by thermogravimetric analysis, rheometer and the tensile test. Thermal results indicated that blends had better thermal oxidation resistance than pure ETFE. Particularly, the initial thermal decomposition temperature $\left(T_{d 0}\right)$ and the temperature at maximum decomposition rate $\left(T_{d \max }\right)$ of PVDF/ ETFE $(10 / 90 \mathrm{wt} \%)$ blends were at $374.49^{\circ} \mathrm{C}$ and $480^{\circ} \mathrm{C}$, which were $52.6^{\circ} \mathrm{C}$ and $34^{\circ} \mathrm{C}$ higher than pure ETFE. The activation energy of thermal degradation $\left(E_{d}\right)$ of ETFE was $66 \mathrm{~kJ} / \mathrm{mol}$, while the PVDF/ETFE (10/90 wt\%) blends presented a higher $E_{d}$, near $187 \mathrm{~kJ} / \mathrm{mol}$. Furthermore, rheological measurements demonstrated that the shear-thinning tendency of blends became stronger with increasing PVDF content. PVDF/ETFE (10/90 wt\%) blends had somewhat lower mechanical properties than ETFE, which was still high enough for various applications. Blends with PVDF provided an efficient method to extend the application area of ETFE.

\footnotetext{
*Corresponding authors: Xianghai Ran, Lab of Polymer Composites Engineering, Changchun Institute of Applied Chemistry, Chinese Academy of Sciences, Changchun, 130022, P.R. China; and University of Science and Technology of China, Hefei, 230026, P.R. China, Phone: +8643185262677 , Fax: +8643185262424 , e-mail: ranxh@ciac.ac.cn; and Wei Nie, Lab of Polymer Composites Engineering, Changchun Institute of Applied Chemistry, Chinese Academy of Sciences, Changchun, 130022, P.R. China; and University of Science and Technology of China, Hefei, 230026, P.R. China, Phone: +86431 85262232, Fax: +86 43185262778 , e-mail:wnie@ciac.ac.cn Jing Qian and Xianyou Wu: Lab of Polymer Composites Engineering, Changchun Institute of Applied Chemistry, Chinese Academy of Sciences, Changchun, 130022, P.R. China; and University of Science and Technology of China, Hefei, 230026, P.R. China Chao Fu: Lab of Polymer Composites Engineering, Changchun Institute of Applied Chemistry, Chinese Academy of Sciences, Changchun, 130022, P.R. China
}

Keywords: activation energy of thermal degradation; PVDF/ETFE; rheological properties; the initial thermal decomposition temperature; thermal stability.

\section{Introduction}

Ethylene-tetrafluoroethylene (ETFE) alternating copolymer is a semi-crystalline polymer which consists of equal amounts of ethylene and tetrafluoroethylene (1). It retains the excellent properties of polytetrafluoroethylene (PTFE) (2). What is more, the radiation resistance and mechanical properties of ETFE are superior to PTFE. ETFE can be processed into coatings, films, foils and cushions for various applications due to its lightweight, high transparency and environment-friendly characteristics (3-8). Because of its prominent properties for diverse applications, ETFE has attracted considerable research attention, particularly in terms of its crystal structure $(9,10)$, rheological properties (11-13), mechanical properties (3), thermal properties (14$17)$ and its relaxation transitions $(18,19)$. ETFE is a thermoplastic material that can be processed repeatedly at high temperature. However, it is easily decomposed during the melting process (20). Despite the importance of its thermal stability during the processing and application of ETFE, studies relating to this issue are few in the literature. So, it is necessary to enhancement the thermal stability of ETFE.

The thermal behavior and thermal properties of the polymer contains two main aspects. One characterizes the thermal stability and kinetic properties from a macroscopic point of view, containing the initial thermal decomposition temperature $\left(T_{d 0}\right)$, the activation energy of thermal degradation $\left(E_{d}\right)$ and the reaction order (20). The other belongs to the mechanism of thermal degradation, and investigates the physical and chemical reactions (21). The $T_{d 0}$ and $E_{d}$ have significant guidance for the processing and service conditions of the material, while the second provides insight into the molecular scale, revealing the molecular structure of the polymer and how it changes during thermal destruction.

Most researchers mainly characterized and explored the thermal properties of ETFE (22-24). Only a few studies 
and patents are linked to enhancing the thermal stability of ETFE. Most stabilizers employed for ETFE are coppercontaining compounds $(25,26)$ and organic stabilizers (20), such as CuI, CuCl, amine- or phenolic- based compounds. However, those heavy metal ions are harmful to the environment and organic stabilizers are easy to volatilize due to the high processing temperature. Thus, developing new stability agents to enhance the thermal resistance of ETFE is essential.

Blending is an effective way to modify the material performance $(27,28)$. Polymer blends could be used for various applications due to its excellent properties. Studies of the blends of ETFE with other polymers are scarce in the literature. Poly(vinylidene fluoride) (PVDF) is a fluoropolymer, it is also lightweight, has high transparency and has environment-friendly characteristics (29). In particular, PVDF and ETFE are isomers; PVDF has a higher thermal decomposition temperature than ETFE. This study mainly focused on the thermal stability of PVDF/ETFE blends. Furthermore, the decomposition kinetic analyses of PVDF/ETFE blends were investigated by thermal gravimetric analysis. The rheological properties were investigated for better evaluation of the melt behavior and microstructure of the blends. The mechanical properties of blends were also investigated. Our method is expected to extend the practical applications of ETFE films in the future.

\section{Experimental}

\subsection{Materials}

Commercial ETFE (C88AXMP) in granular form with a melt flow rate of $30 \mathrm{~g} / 10 \mathrm{~min}\left(290^{\circ} \mathrm{C} / 5 \mathrm{~kg}\right)$ and a specific gravity of 1.73 was purchased from AGC Chemicals Co., Ltd. (Japan). The PVDF (Kynar 460) used in this study was obtained from Arkema Co., Ltd. (France). The melt flow index (MFI) reported by the supplier was $16-30 \mathrm{~g} / 10 \mathrm{~min}$ $\left(230^{\circ} \mathrm{C} / 5 \mathrm{~kg}\right)$. All specimens were dried in an oven at $80^{\circ} \mathrm{C}$ overnight to remove excess moisture.

\subsection{Blend preparation}

PVDF/ETFE mixtures with ratios of 0/100, 10/90, 20/80, 30/70, 50/50 and 100/0 wt/wt were blended with a corotating twin-screw extruder (Mini Lab II, Thermo Haake, Germany). The experimental temperature was maintained at $280^{\circ} \mathrm{C}$, the screw speed was maintained at $60 \mathrm{rpm} / \mathrm{min}$ and the blend time was $10 \mathrm{~min}$ for all specimens. Moreover, all samples were pushed into a flat vulcanizing machine and cooled under air. The cooled sample was obtained with the thickness of $1 \mathrm{~mm}$, and then cut into a dumbbell shape for tensile test.

\subsection{Characterization}

\subsubsection{Thermal stability}

Thermo gravimetric analysis (TGA) was performed with a Mettler-Toledo (TGA/SDTA 851, Switzerland) thermal balance. The sample was cut from the composites at around $8 \mathrm{mg}$ and heated from $50^{\circ} \mathrm{C}$ to $100^{\circ} \mathrm{C}$, held isothermally for $10 \mathrm{~min}$, and then heated up to $800^{\circ} \mathrm{C}$ at a rate of $10^{\circ} \mathrm{C} / \mathrm{min}$ in air. For the kinetic analysis, different heating rates of $10,15,20$ and $25^{\circ} \mathrm{C} / \mathrm{min}$ were used for the isoconversional method analysis $(30,31)$.

\subsubsection{Rheological measurements}

Rheological measurements of the PVDF/ETFE blends were conducted with a rheometer (AR 200ex, TA Instruments Co., USA). A frequency sweep for all the samples was carried out under $\mathrm{N}_{2}$ atmosphere using $25 \mathrm{~mm}$ plate-plate geometry. The gap distance between the parallel plates was $0.9 \mathrm{~mm}$ for all tests. The angular frequency range used during testing was $0.1-100 \mathrm{rad} / \mathrm{s}$ at $280^{\circ} \mathrm{C}$.

\subsubsection{Mechanical properties testing}

The mechanical properties tests were carried out on a universal material testing machine (Instron5869, INSTRON Co., Ltd., USA) at room temperature according to ASTM D638. The gage length was $50 \mathrm{~mm}$, and the testing speed was $10 \mathrm{~mm} / \mathrm{min}$. Five composite specimens were tested for each set of samples. The reported value was the average of five replicates for each property test. The principal result obtained from a tension test is a graph of axial force vs. gage length for the entire test. The value of the stress and strain was calculated by the following equations:

$$
\begin{gathered}
\sigma=\frac{P}{A_{i}} ; \\
\varepsilon=\frac{L-L_{i}}{L_{i}}=\frac{\Delta L}{L_{i}} ;
\end{gathered}
$$




$$
\tilde{\sigma}=\frac{P}{A}=\sigma \frac{A_{i}}{A}
$$

and

$$
\tilde{\varepsilon}=\ln \frac{A_{i}}{A},
$$

where $P$ means the axial force; $A$ means the current cross-sectional area; $A_{i}$ means the initial cross-sectional area; $\Delta L$ means the change of gage length; $L$ means the gage length after deformation; $L_{i}$ means the initial gage length; $\sigma$ means the engineering stress; $\varepsilon$ means the engineering strain; $\tilde{\sigma}$ means the true stress and $\tilde{\varepsilon}$ means the true strain (32).

\section{Results and discussion}

\subsection{Thermogravimetric analysis and kinetics}

The thermal stability of PVDF/ETFE blends was investigated by TGA. As shown in Figure 1A ETFE begins to decompose at a lower temperature than PVDF. All the blend degradation curves are displayed between pure PVDF and pure ETFE, the initial decomposition temperature $\left(T_{d 0}\right)$ is changed with the increasing of the PVDF contents. The order of the initial thermal stability from the weakest to the best is pure ETFE, PVDF/ETFE (20/80 wt\%), PVDF/ETFE (30/70 wt\%), PVDF/ETFE (50/50 wt\%) and PVDF/ETFE (10/90 wt\%). PVDF/ETFE (10/90 wt\%) indicated the better results than other blends. This behavior is also seen from Figure 1B, which is the differential curve for Figure 1A. The results demonstrate that ETFE film has only one peak during the thermal degradation process. The blends show the same decomposition trend as pure ETFE at low PVDF content.

The thermal decomposition parameters of blends with different PVDF contents are shown in Table 1 . The $T_{d 0}$ and $T_{d \max }$ of pure ETFE are at $321.85^{\circ} \mathrm{C}$ and $446^{\circ} \mathrm{C}$, respectively. In particular, the $T_{d 0}$ of PVDF/ETFE (10/90 wt $\%$ ) is at $374.49^{\circ} \mathrm{C}$, which is $52.6^{\circ} \mathrm{C}$ higher than pure ETFE. Furthermore, the $\mathrm{T}_{d \max }$ of PVDF/ETFE (10/90 wt\%) blends is at $480^{\circ} \mathrm{C}$, which is $34^{\circ} \mathrm{C}$ higher than pure ETFE. The blends shows different thermal decomposition behavior compare to pure ETFE. ETFE begins to decompose in slow reaction rates between $340^{\circ} \mathrm{C}$ and $400^{\circ} \mathrm{C}$, and the blends of PVDF/ $\operatorname{ETFE}(10 / 90 \mathrm{wt} \%$ ) do not decompose until the temperature reaches $370^{\circ} \mathrm{C}$. Curiously, the $T_{d 0}$ of blends are increased with the increases of PVDF content (0-10\%), and then decreased when PVDF content increases even further.

According to the Kinetics Committee of the International Confederation for Thermal Analysis and Calorimetry (ICTAC) recommendation, to perform a kinetic analysis on polymer decomposition, isoconversional methods are preferred (33). Isoconversional methods employ multiple
A

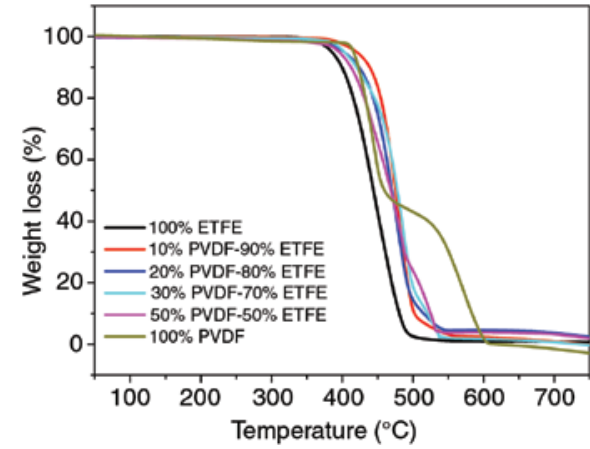

B

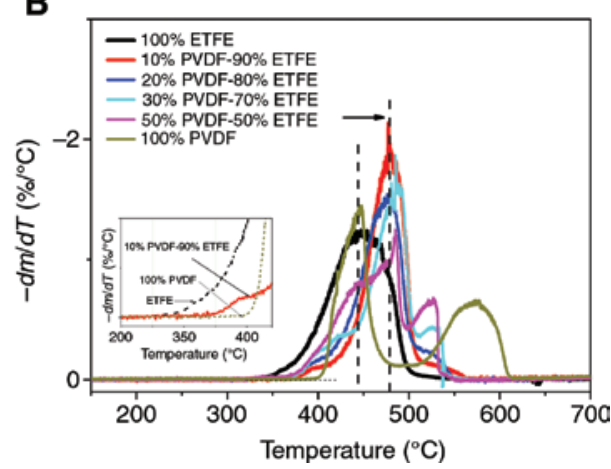

Figure 1: TGA curves (A) and DTGA curves (B) of PVDF/ETFE blends of different mixture at the heating rates of $10^{\circ} \mathrm{C} / \mathrm{min}$ in air.

\begin{tabular}{|c|c|c|c|c|c|}
\hline$w(P) / w(E)$ & $10 \% / 90 \%$ & $20 \% / 80 \%$ & $30 \% / 70 \%$ & $50 \% / 50 \%$ & Pure ETFE \\
\hline $\mathrm{T}_{d 0}\left({ }^{\circ} \mathrm{C}\right)$ & 374.49 & 361.13 & 367.02 & 368.37 & 321.83 \\
\hline $\mathrm{T}_{d \max }\left({ }^{\circ} \mathrm{C}\right)$ & 480 & 477 & 485 & $485 / 528$ & 446 \\
\hline $\mathrm{E}_{d}(\mathrm{~kJ} / \mathrm{mol})$ & 187.2 & - & - & - & 66 \\
\hline
\end{tabular}

Table 1: Thermal decomposition parameters of blends with different PVDF content in air. 
A

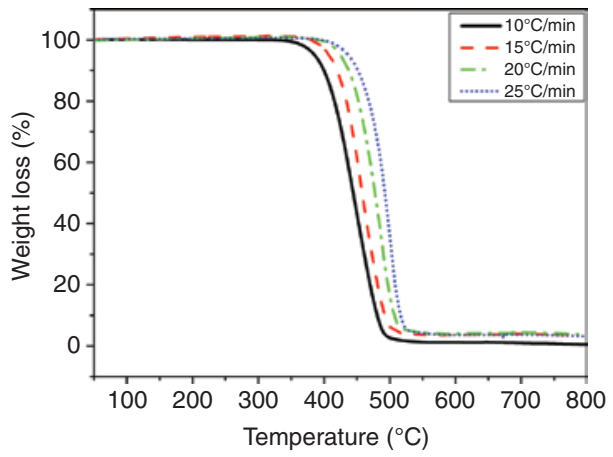

B

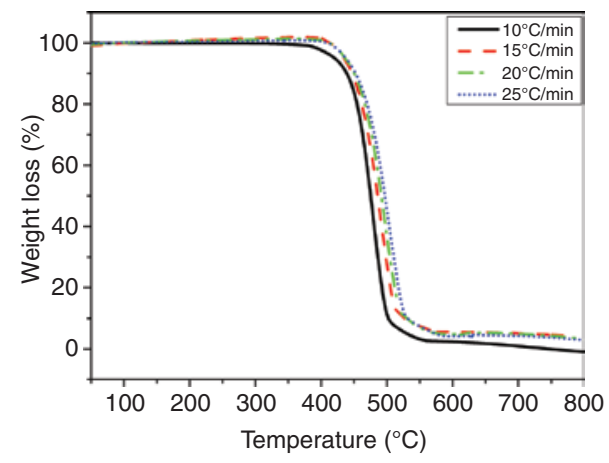

Figure 2: TGA cures of samples with different heating rates: pure ETFE (A) and PVDF/ETFE (10/90 wt\%) blends (B).

temperature programs in order to obtain data on varying rates at a constant extent of conversion $(34,35)$. Thus, for the thermal decomposition kinetic analysis, all samples were heated in air at four different heating rates. As PVDF/ETFE (10/90 wt\%) has the best thermal resistance, we just need to compare the $E_{d}$ of PVDF/ETFE (10/90 wt\%) with pure ETFE. As shown in Figure 2, as it is common in polymer degradation, increased heating rates results in shifting of the degradation curves in higher temperatures.

Generally, in thermogravimetric measurements, the degree of decomposition $(\alpha)$ is calculated by

$$
\alpha=\frac{m_{0}-m_{t}}{m_{0}-m_{f}},
$$

where $m_{0}, m_{t}$ and $m_{f}$ are initial, actual and final masses of the sample, respectively (36). A typical model for the kinetic process can be expressed as

$$
\frac{d \alpha}{d t}=k f(\alpha)
$$

where $d \alpha / d t$ is the decomposition rate; $f(\alpha)$ is a parameter which depends on the particular decomposition mechanism; $k$ is the decomposition rate constant, which can be expressed by the Arrhenius equation:

$$
\mathrm{k}=A \exp \left(\frac{-E_{d}}{R T}\right)
$$

where $A$ is the pre-exponential factor $\left(\mathrm{s}^{-1}\right) ; R$ is the gas constant; $T$ is absolute temperature (k); $E_{d}$ is the activation energy of thermal degradation $(\mathrm{J} / \mathrm{mol})$. By a combination of equation [6] and the Arrhenius equation, we obtain:

$$
\frac{d \alpha}{d t}=A \exp \left(\frac{-E_{d}}{R T}\right) f(\alpha)
$$

If the temperature of a sample is changed by a constant value of heating rate $\varphi(\varphi=d T / d t)$, the variation of the degree of decomposition can analyzed as a function of temperature. Therefore, the reaction rate gives:

$$
\frac{d \alpha}{d T}=\frac{A}{\varphi} \exp \left(\frac{-E_{d}}{R T}\right) f(\alpha) .
$$

There are a number of primary analytical methods which were improved from these equations to calculate the activation energy and other related factors, such as the Ozwa-Flynn-Wall method $(31,37)$, the Friedman method (33) and the advanced integral isoconversional method by Vyazokin (38). In our work, the Ozwa-Flynn-Wall method, as the most widely used method for kinetic analysis, is used to study the thermal properties of the polymer composites. According to the Ozwa-Flynn-Wall method, the principle is shown in Eq. [9]:

$$
\lg \varphi=\lg \frac{A E}{R}-\lg \left[\int_{0}^{\alpha} \frac{1}{(1-\alpha)^{n}} d \alpha\right]-0.4567 \frac{E_{d}}{R T}+C,
$$

where $C$ is the constant. Then the value of $E_{d}$ can be determined from the plots of $\lg \varphi$ vs. $1 / T$, obtained from each thermogram at constant values of $\alpha$. Then a set of straight lines can be obtained at different conversion periods, with the slope of each line being $-0.4567 E_{d} / R$.

The $E_{d}$ calculations for pure ETFE and one of the PVDF/ETFE (10/90 wt\%) blends are presented in Figure 3, which was obtained using the Ozwa-FlynnWall method. As shown in Table 1, the $E_{d}$ of pure ETFE is $66 \mathrm{~kJ} / \mathrm{mol}$, whereas PVDF/ETFE (10/90 wt\%) had high thermal degradation activation energy at approximately $187 \mathrm{~kJ} / \mathrm{mol}$. Hence, the higher $E_{d}$ value of PVDF/ETFE $(10 / 90 \mathrm{wt} \%)$ indicates that it has better thermal oxidation resistance than pure ETFE. Good thermal stabilities are found for pure ETFE films at about $321^{\circ} \mathrm{C}$ and PVDF/ ETFE $(10 / 90 \mathrm{wt} \%)$ blends at about $375^{\circ} \mathrm{C}$. The same trend can be seen in that PVDF/ETFE (10/90 wt\%) blends have 

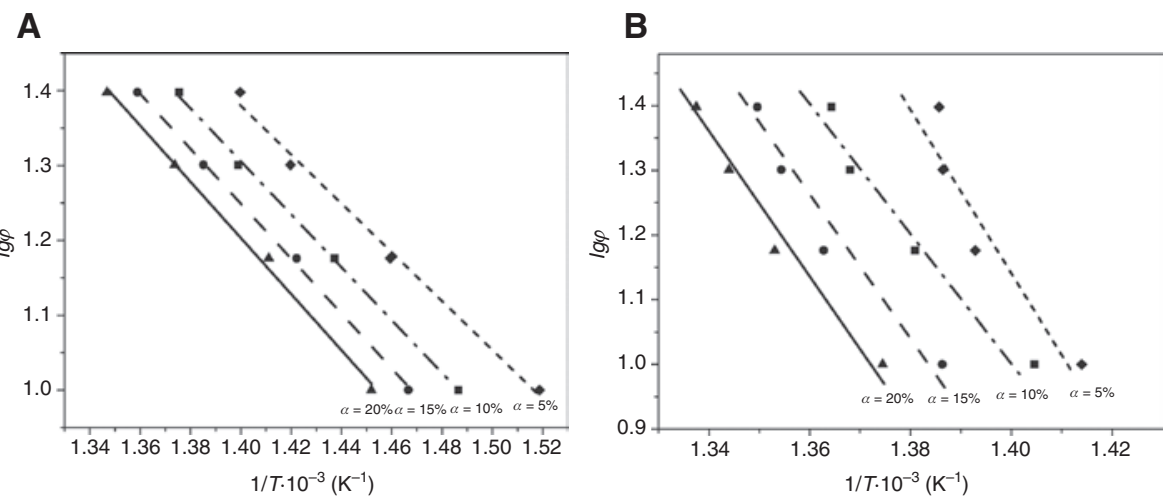

Figure 3: Calculation of thermal degradation activation energy based on the nonisothermal dynamic thermal kinetic model for pure ETFE (A) and PVDF/ETFE (10/90 wt\%) (B).

the biggest activation energy, which is high enough for various applications.

\subsection{Rheological properties}

Dynamic rheological experiments were carried out in the PVDF/ETFE films with the different compositions. The frequency dependence of oscillatory shear modulus under nitrogen atmosphere at $280^{\circ} \mathrm{C}$ with different PVDF content is shown in Figure 4. It is found that the storage modulus $\left(G^{\prime}\right)$ and loss modulus $\left(G^{\prime \prime}\right)$ is increased with the increasing of PVDF content, especially in the low angular frequency. At high angular frequency, the qualitative behaviors of storage modulus and loss modulus are essentially similar and not obviously affected by the existence of PVDF
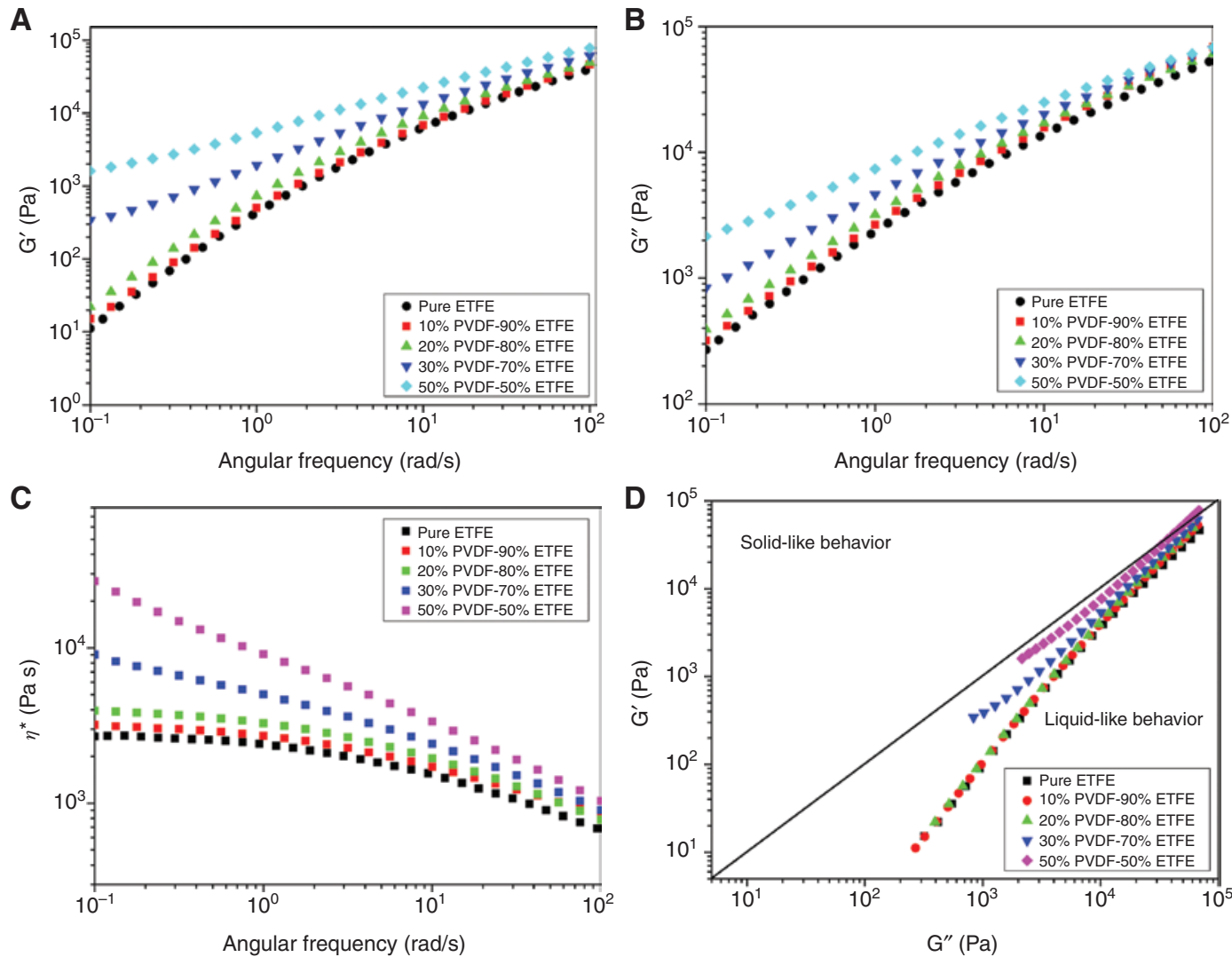

Figure 4: Rheology properties of PVDF/ETFE samples with different ratio: (A) G'vs. frequency, (B) G" vs. frequency, (C) $\eta^{*}$ vs. frequency and (D) G' vs. G". 
content. As PVDF content increases up to $30 \mathrm{wt} \%$, the slopes of the modulus curves change significantly. This phenomenon reveals that the entanglements between PVDF chains and ETFE chains are formed.

As shown in Figure 4C, it is demonstrated that the existence of PVDF has a dramatic effect on the complex viscosity $\left(\eta^{*}\right)$ of the blends. In the low angular frequency, it can be clearly seen that the PVDF/ETFE (10/90 wt \%) film show the Newtonian fluid plateau and the $\eta^{*}$ do not change with the angular frequency. Meanwhile, with increasing PVDF content up to $30 \mathrm{wt} \%$, the viscosity curves of blends show non-Newtonian shear thinning behaviors and there is no plateau region under the whole angular frequency range. In particular, we observe that the PVDF/ETFE (50/50 wt\%) film displays a value of a few orders of magnitude greater than that of low PVDF content. The increase of the $\eta^{*}$ of the PVDF/ETFE films can be attributed to the entanglements between the PVDF chains and ETFE chains. This remarkable enhancement in the melt viscosity of PVDF/ ETFE blends led to an increase in melt strength, which was beneficial to the processing of blown films.

The plot of $G^{\prime}$ vs. $G^{\prime \prime}$ from the dynamic rheological measurements, also known as a Han plot, was used to characterize the anisotropic-isotropic transition. This plot allowed analysis of the material properties and the interaction between each component during the melting process. The ratio of the moduli is $\mathrm{K}$, where $\mathrm{K}=\left(\log \mathrm{G}^{\prime}\right)$ / $\left(\log G^{\prime \prime}\right)$. The material displays liquid-like behavior during the melting process if $\mathrm{K}<1$; solid-like behavior will predominate if $\mathrm{K}>1$. The melting properties of blends are shown in Figure 4D. Results show a tendency from liquid-like behavior to pseudo solid-like behavior with the increase of PVDF contents.

\subsection{Mechanical properties}

Figure 5A indicates the engineering stress-strain curves of all the PVDF/ETFE blends. Fracture behavior of the specimen in the tensile tests changed from ductile to brittle fractures with the increase of PVDF content. The yield strength of ETFE decreased slightly when the PVDF content changed from $0 \%$ to $10 \%$. After that step, the material properties changed rapidly. The area under the stress-strain curve is a measure of toughness. Furthermore, toughness of the PVDF/ETFE blends decreased with the increase in PVDF content.

As Figure 5A displays, PVDF/ETFE blends display the feature of relatively low yield strength and large strain. In order to further investigate the fracture behavior of blends, the true stress-strain curve of PVDF/ETFE blends is shown in Figure 5B. The engineering and true stress-strain curves of blends exhibit a similar trend with the increase of PVDF content. At the elastic deformation region, stress can be directly obtained when the deformation is uniform by measuring the force and the corresponding cross-sectional area. As Figure 5C demonstrates that the difference between true and engineering stress-strain of PVDF/ETFE (10/90 wt\%) is generally so small that it can be neglected. Once necking starts at the engineering ultimate stress point, the engineering strain becomes merely an average over a region of non-uniform deformation. That means true stresses can be calculated only if the varying minimum cross-sectional area in the necked region is measured. As shown in Figure 5C, the true stress is much higher than the engineering stress after necking, which can be attributed to the decreases of cross-sectional areas during the tensile testing. It has been found that the true stress and true strain of PVDF/ETFE blends are decreased with the increase of PVDF content, which demonstrates the intermolecular interaction and chain regularity of blends decreased at high PVDF content and made the blends easily fracturable. The rise in the true stress-strain curve following yielding demonstrates that the strain hardening occurs with the increase of deformation after necking.

The tensile strength data are presented in Figure 5D as a function of composition. The tensile strength of ETFE decrease with the blend of PVDF content and decrease from 43.02 to $15.02 \mathrm{MPa}$ upon increasing the PVDF content from $0 \%$ to $50 \%$. The reduction in tensile strength of PVDF/ETFE blends is expected given that PVDF has lower modulus and tensile strength compared to ETFE. However, the tensile strength of PVDF/ETFE (10/90 wt\%) blends was at $34.33 \mathrm{MPa}$, which is almost $9 \mathrm{MPa}$ lower than pure ETFE. As shown in Figure 5D, the decrease of tensile strength at blends ranging from $0 \%$ to $50 \%$ weight fraction of PVDF indicated that PVDF blending in this regime simply diluted the ETFE matrix. As for the flat trend in PVDF components ranging from $30 \%$ to $50 \%$, some reinforcements may have been due to interactions between ETFE and PVDF; otherwise, a similar reduction would be observed in those samples.

As can be seen in Figure 5E, Young's modulus of blends is found to be less than that of pure ETFE. Young's modulus decreases with increasing PVDF content. As shown in Figure 5F, the elongation at break curves is observed. The elongation at break of PVDF/ETFE (10/90 wt\%) is similar to pure ETFE. Tensile strength and elongation at break are decreased when the PVDF content increases beyond $20 \%$. In particular, no significant differences are found at low PVDF content. 
A
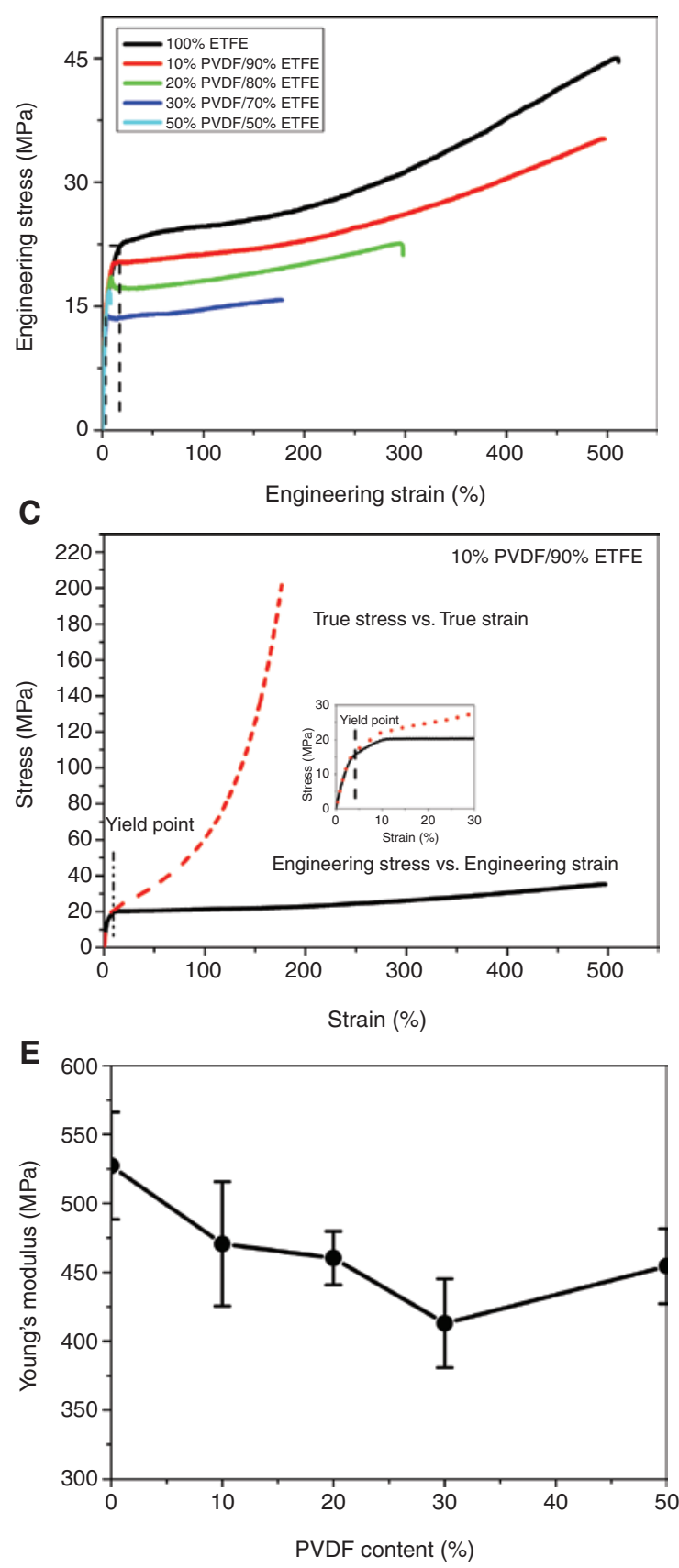

B

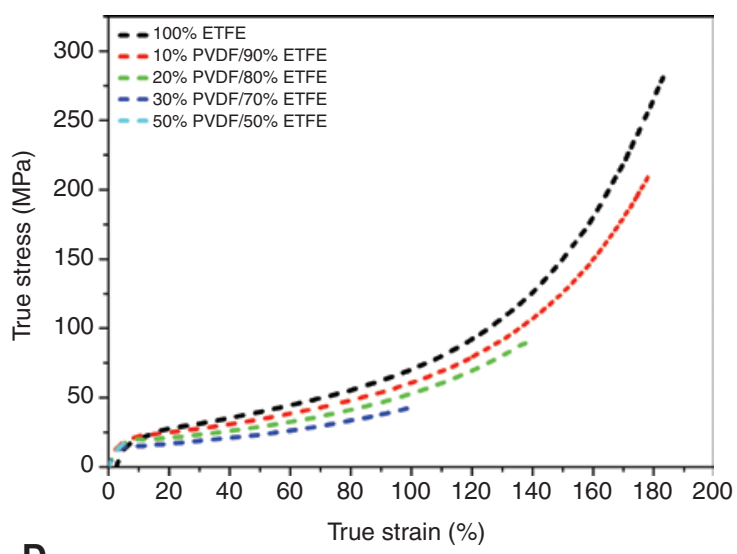

D

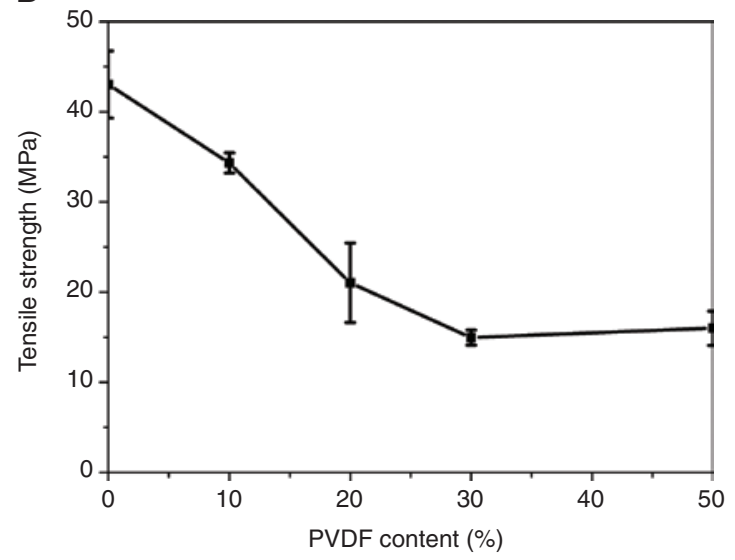

$\mathbf{F}$

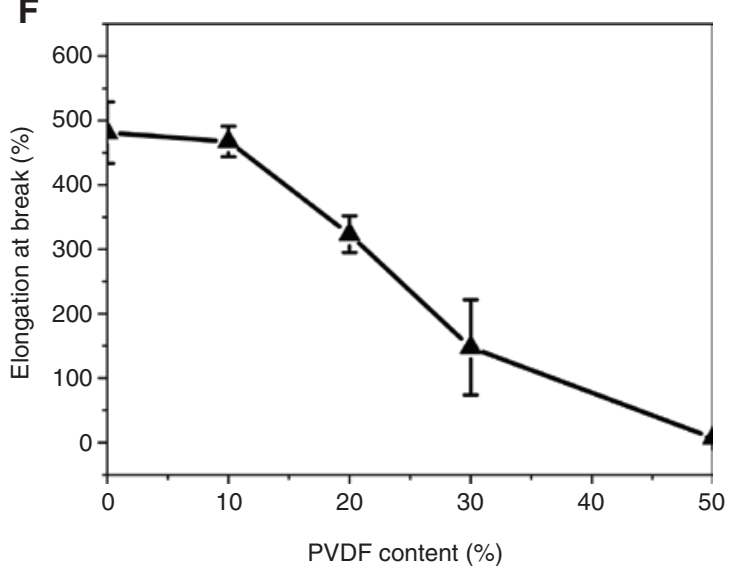

Figure 5: Mechanical properties of blends with different PVDF content: (A) engineering stress vs. strain, (B) true stress vs. strain, (C) stressstrain curve for PVDF/ETFE (10\%/90\% wt), (D) tensile strength, (E) Young's modulus and (F) elongation at break.

\section{Conclusions}

In this work, the thermal stability, rheology and mechanical properties of PVDF/ETFE blends were investigated by TGA, rheological measurements and tensile tests in detail. The results revealed that the thermal stability was remarkably improved after blending with PVDF contents. Upon adding $10 \%$ PVDF, the $T_{d 0}$ was $374.49^{\circ} \mathrm{C}$, which was $52.6^{\circ} \mathrm{C}$ higher than the $T_{d 0}$ of pure ETFE. Moreover, it was found that pure ETFE has the lower $E_{d}(66 \mathrm{~kJ} / \mathrm{mol})$ while PVDF/ ETFE (10/90 wt\%) presented a higher $E_{d}$, near $187 \mathrm{~kJ} / \mathrm{mol}$. Based on rheological studies, entanglement densities of blends were increased with the increase of PVDF phase. The melt property displayed a tendency from liquid-like 
behavior to pseudo solid-like behavior with the increase of PVDF contents. Finally, the mechanical properties revealed that $0-10 \%$ of PVDF used in blends that may result in decrease of the tensile properties. The pure ETFE had the best tensile properties, while PVDF/ETFE (10/90 wt $\%)$ blends had a little lower mechanical properties, which was still high enough for various applications. PVDF/ETFE (10/90 wt\%) blends have a wide processing temperature range and this material has good processing performance.

Acknowledgments: The authors gratefully acknowledge financial support from the Jilin Provincial Development and Reform Commission Funding 2016C012.

\section{Compliance with ethical standards}

Conflict of interest: The authors declare that they have no competing interests.

\section{References}

1. Zhang Y, Li H, Zhang H. Fluorine-containing functional materials. Beijing, China: Chemical Industry Press; 2008.

2. Holding S. Technology of fluoropolymers. Chromatographia 2010;71:173.

3. Zhao B, Chen W, Hu J, Chen J, Qiu Z, Zhou J, Gao C. Mechanical properties of ETFE foils in form-developing of inflated cushion through flat-patterning. Constr Build Mater. 2016;111:580-9.

4. Charbonneau L, Polak MA, Penlidis A. Mechanical properties of ETFE foils: testing and modelling. Constr Build Mater. 2014;60:63-72.

5. Hu J, Chen W, Zhao B, Yang D. Buildings with ETFE foils: a review on material properties, architectural performance and structural behavior. Constr Build Mater. 2017;131:411-22.

6. Osorio AF, Mizutani K, Fernandez-Pello C, Fujita O. Microgravity flammability limits of ETFE insulated wires exposed to external radiation. Proc Combust Inst. 2015;35:2683-9.

7. Abdolzadeh M, Sadeqkhani M, Ahmadi A. Computational modeling of a BIPV/T ethylene tetrafluoroethylen (ETFE) cushion structure roof. Energy 2017;133:998-1012.

8. Tomihashi N, Ogita K, Miyatani T, Nakatani Y, inventors; Fluorine-containing resin coating compositions, primers for ETFE coating, and coated articles. Google Patents; 2007.

9. Funaki A, Phongtamrug S, Tashiro K. Crystal structure analysis of ethylene-tetrafluoroethylene alternating copolymer. Macromolecules 2011;44:1540-8.

10. Miranda DF, Yin C, Zhang S, Runt J. Fluoropolymer microstructure and dynamics: influence of molecular orientation induced by uniaxial drawing. Polymer 2016;91:211-21.

11. Kotera S, Yamaguchi M. Flow property at capillary extrusion for ethylene-tetrafluoroethylene copolymer. J Fluor Chem. 2015;176:20-5.

12. Kotera S, Yamaguchi M. Rheological characterization on thermal degradation of ethylene-tetrafluoroethylene copolymer. J Fluor Chem. 2014;166:117-21.
13. Tuminello WH, Buck WH, Kerbow DL. Rheological molecular weight distribution determinations of ethylene/tetrafluoroethylene copolymers: implications for long-chain branching. Macromolecules 1993;26:499-503.

14. Giannetti E. Thermal stability and bond dissociation energy of fluorinated polymers: a critical evaluation. J Fluor Chem. 2005;126:623-30.

15. Gürsel SA, Schneider J, Ben Youcef H, Wokaun A, Scherer GG. Thermal properties of proton-conducting radiation-grafted membranes. J Appl Polym Sci. 2008;108:3577-85.

16. Hondred PR, Yoon S, Bowler N, Kessler MR. Degradation kinetics of polytetrafluoroethylene and poly(ethylene-alt-tetrafluoroethylene). High Perform Polym. 2013;25:535-42.

17. Chen XY, Yuan WZ, Ai F, LiLei H, Wang J, Zhang Y. Melt rheological properties of ETFE: an attempt to illuminate the fluorine-substitution effect. Polym Bull. 2012;69:375-88.

18. Hu J, Chen W, Liu Y, Zhao B, Gao C, Yang D. Dynamic mechanical analysis of ethylene tetrafluoroethylene (ETFE) foils in use for transparent membrane buildings. Polym Test. 2017;59:118-26.

19. Kostov G, Nikolov A, Atanassov A. Study of the thermal properties and relaxation transitions in tetrafluoroethene-ethene copolymers. J Appl Polym Sci. 2001;81:2626-32.

20. Chen XY, Yuan WZ, Zhao J, Yang L, Li H, Li L, Zhang Y. Thermal-mechanical stability of ethylene tetrafluoroethylene alternating copolymer, and modification thereof. J Polym Res. 2012;19:1-6.

21. Chuang TH, Guo W, Cheng KC, Chen SW, Wang HT, Yen YY. Thermal properties and flammability of ethylene-vinyl acetate copolymer montmorillonite polyethylene nanocomposites with flame retardants. J Polym Res. 2004;11:169-74.

22. Morelli JJ, Fry CG, Grayson MA, Lind AC, Wolf CJ. The thermal oxidative degradation of an ethylene-tetrafluoroethylenecopolymer-based electrical wire insulation. J Appl Polym Sci. 1991;43:601-11.

23. Morelli JJ, Sandreczki TC. The vacuum pyrolysis and thermal degradation in air of irradiated poly(ethylene-co-tetrafluoroethylene) films. J Anal Appl Pyrolysis 1995;35:121-41.

24. Loginova NN, Madorskaya LY, Podlesskaya NK. Relations between the thermal stability of partially fluorinated polymers and their structure. Polym Sci. 1983;25:2575-9.

25. Anderson JC. Stabilized ethylene/tetrafluoroethylene copolymers. Google Patents; 1983.

26. Hartwimmer R, Kuhls J. Stabilized copolymers based on ethylene and tetrafluoroethylene, and processes for their preparation. Google Patents; 1981.

27. Mikitaev AK, Ligidov MK, Zaikov GE. Polymers, polymer blends, polymer composites and filled polymers: synthesis, properties and applications. New York: Nova Science Publishers; 2006.

28. Schwahn D. Critical to mean field crossover in polymer blends. Adv Polym Sci. 2005;183:1-63.

29. Li R, Xue B, Pei J. Enhancement of the dielectric performance of PA11/PVDF blends by a solution method with dimethyl sulfoxide. e-Polymers 2015;15:439-45.

30. Yao F, Wu Q, Lei Y, Guo W, Xu Y. Thermal decomposition kinetics of natural fibers: activation energy with dynamic thermogravimetric analysis. Polym Degrad Stab. 2008;93:90-8.

31. Ozawa T. A new method of analyzing thermogravimetric data. Bull Chem Soc Jpn. 1965;38:1881-6.

32. Ling Y. Uniaxial true stress-strain after necking. Amp Incorporated Amp J Technol. 2004;5:37-48. 
33. Vyazovkin S, Burnham AK, Criado JM, Pérez-Maqueda LA, Popescu C, Sbirrazzuoli N. ICTAC Kinetics Committee recommendations for performing kinetic computations on thermal analysis data. Thermochimica Acta 2011;520:1-19.

34. Mamleev V, Bourbigot S, Yvon J. Kinetic analysis of the thermal decomposition of cellulose: the main step of mass loss. J Anal Appl Pyrolysis 2007;80:151-65.

35. Terzopoulou Z, Tsanaktsis V, Nerantzaki M, Achilias DS, Vaimakis T, Papageorgiou GZ, Bikiaris DN. Thermal degradation of biobased polyesters: kinetics and decomposition mechanism of polyesters from 2,5-furandicarboxylic acid and long-chain aliphatic diols. J Anal Appl Pyrolysis 2016;117:162-75.

36. Li H, Kim H. Thermal degradation and kinetic analysis of PVDF/ modified MMT nanocomposite membranes. Desalination 2008;234:9-15.

37. Liu ZH. Introduction of thermal analysis. Beijing: ChemistryIndustry Press; 1991:73.

38. Vyazovkin S. Modification of the integral isoconversional method to account for variation in the activation energy. J Comput Chem. 2001;22:178-83. 